\title{
Synthesis, Self-Assembly, and Photoresponsive Behavior of Tadpole-Shaped Azobenzene Polymers
}

Xing Wang, ${ }^{*}$ Yanyu Yang, Peiyuan Gao, Fei Yang, Hong Shen, Hongxia Guo, and Decheng Wu* Beijing National Laboratory for Molecular Sciences, State Key Laboratory of Polymer Physics \& Chemistry, Institute of Chemistry, Chinese Academy of Sciences, Beijing 100190, China 


\section{Materials}

Octavinyl POSS (98\%, Hybrid Plastics), trifluoromethanesulfonic acid (99\%, Aldrich), poly(ethylene glycol) methyl ether (PEG-OH, $M_{\mathrm{n}}=350 \mathrm{~g} / \mathrm{mol}$, Alfa Aesor), succinic anhydride (99\%, J\&K), 1-(3-dimethylaminopropyl)-3-ethylcarbodiimide hydrochloride (EDCI, 99\%, Energy Chemical), 2,2-dimethoxy-2-phenylacetophenone (DMPA, 99\%, J\&K), 4-phenylazophenol (98\%, Alfa Aesar), 1,3-dibromopropane (99\%, J\&K), thiocarbamide (99\%, J\&K), 4-(dimethyl-amino)-pyridine (DMAP, 99\%, Aldrich), triethylamine (TEA, 99\%, Beijing Chemical Works), sodium hydroxide, hydrochloric acid, ethanol, ethyl acetate, petroleum ether, n-hexane and ether (reagent grade, Beijing Chemical Works), tetrahydrofuran (THF) and dichloromethane $\left(\mathrm{CH}_{2} \mathrm{Cl}_{2}\right)$ were purified by stirring over calcium hydride for $24 \mathrm{~h}$ followed by distillation. All other reagents were purchased from Sigma-Aldrich and used as received without further purification.

\section{Characterizations}

${ }^{1} \mathrm{H}$ and ${ }^{13} \mathrm{C}$ NMR spectra were obtained on a Bruker DRX-400 spectrometer in chloroform- $\mathrm{d}$ using tetramethylsilane (TMS) as internal reference. Gel permeation chromatography (GPC) measurements were carried out on GPCmax VE-2001 (Viscotek) equipped with a Viscotek TriSEC Model 302 triple detector array (refractive index detector, viscometer detector, and laser light scattering detector) using two I-3078 Polar Organic Columns. Tetrahydrofuran was used as the eluent at a flow rate of $1.0 \mathrm{~mL} \mathrm{~min}{ }^{-1}$. Molecular weight $\left(M_{\mathrm{n}}\right.$ and $\left.M_{\mathrm{w}}\right)$ and polydispersity indexes (PDI) were obtained using the workstation software equipped with the system by the processing method for dendritic polymers based on a working curve of polystyrene standards. Transmission electron microscopy (TEM) images were obtained on a JEM-2200FS microscope (JEOL, Japan). A $5 \mu \mathrm{L}$ droplet of micellar solution was dropped onto a copper grid (300 mesh) coated with a carbon film, followed by drying at room temperature. Cryo-TEM samples were prepared in a controlled environment vitrification system (CEVS) at $28^{\circ} \mathrm{C}$. The vitrified samples were then stored in liquid nitrogen until they were transferred to a cryogenic sample holder (Gatan 626) and examined using a JEM-2200FS TEM (200 KV) at about $-174{ }^{\circ} \mathrm{C}$. Field emission scanning electron microscopy (SEM) images were obtained at acceleration voltage of $5 \mathrm{kV}$ on a JSM-6700F microscope (JEOL, Japan). The samples were sputter-coated with a thin layer of Pt 
for $120 \mathrm{~s}$ to make the samples conductive before testing. Dynamic light scattering (DLS) spectra were obtained on a commercial laser light scattering spectrometer (ALV/DLS/SLS-5022F) equipped with a multi- $\tau$ digital time correlator (ALV5000) and a cylindrical $22 \mathrm{~mW}$ UNIPHASE He-Ne laser $\left(\lambda_{0}=632.8 \mathrm{~nm}\right)$ was used. All data were averaged over three time measurements. The laser light scattering cell is held in a thermostat index matching vat filled with purified and dust-free toluene, with the temperature controlled to within $0.1^{\circ} \mathrm{C}$. UV-vis spectra of the samples were measured over different irradiation time intervals on a Hitachi U-3010 spectrometer, and fluorescence measurements were carried out on a Hitachi F4600 photoluminescence spectrometer with a xenon lamp as a light source.

Synthesis of the septvinyl monohydroxyl POSS, (vinyl) $)_{7}-\mathrm{POSS}-\mathrm{OH}$ ( $\mathrm{AB}_{7}$ monomer). To a solution of octavinyl POSS $(1.9 \mathrm{~g}, 3 \mathrm{mmol})$ in $200 \mathrm{~mL}$ of fresh distilled $\mathrm{CH}_{2} \mathrm{Cl}_{2}$, trifluoromethanesulfonic acid $(0.27 \mathrm{~mL}, 3 \mathrm{mmol})$ was slowly added via syringe at room temperature. After 4 hours, the solution was diluted with $\mathrm{CH}_{2} \mathrm{Cl}_{2}$ and then washed with saturated aqueous $\mathrm{Na}_{2} \mathrm{CO}_{3}$ three times. The organic layer was then concentrated by evaporating the excess solvent. Then wet acetone was added into the concentrated solution and the hydrolysis process was performed for $6 \mathrm{~h}$. The crude product was yielded after removing the solvent. The final product was separated chromatographically on silica gel with $\mathrm{CH}_{2} \mathrm{Cl}_{2} /$ hexane $(\mathrm{v} / \mathrm{v}=2 / 1, \mathrm{Rf}=$ $0.4)$ to afford the white solid with $32.1 \%$ yield. ${ }^{1} \mathrm{H}$ NMR $\left(\mathrm{CDCl}_{3}, 400 \mathrm{MHz}, \mathrm{ppm}\right): \delta 1.62(\mathrm{~s}, 1 \mathrm{H}$, $-\mathrm{OH}), 1.22\left(\mathrm{t}, 2 \mathrm{H},-\mathrm{SiCH}_{2}-\right), 3.82\left(\mathrm{t}, 2 \mathrm{H},-\mathrm{CH}_{2} \mathrm{OH}\right)$, 5.85-6.16 (m, $21 \mathrm{H}$, vinyl- $\left.\mathrm{H}\right) .{ }^{13} \mathrm{C} \mathrm{NMR}$ $\left(\mathrm{CDCl}_{3}, 400 \mathrm{MHz}, \mathrm{ppm}\right): \delta 17.3,58.5,128.6,137.2$.

Synthesis of the carboxyl-terminated mPEG, PEG-COOH. PEG-OH $\left(M_{\mathrm{n}}=350 \mathrm{~g} / \mathrm{mol}, 7 \mathrm{~g}\right.$, $20 \mathrm{mmol})$ and TEA $(1.4 \mathrm{~mL}, 10 \mathrm{mmol})$ were dissolved in $40 \mathrm{~mL}$ of fresh distilled $\mathrm{CH}_{2} \mathrm{Cl}_{2}$, and then succinic anhydride $(2.2 \mathrm{~g}, 22 \mathrm{mmol})$ was added into the solution. After stirring at room temperature for $3 \mathrm{~h}$, the mixture was washed with $2 \mathrm{M} \mathrm{HCl}$ aqueous solution, saturated $\mathrm{NaCl}$ aqueous solution and DI water for three times and dried over anhydrous $\mathrm{Na}_{2} \mathrm{SO}_{4}$. After evaporating the solvent, the residue was dissolved in $\mathrm{CH}_{2} \mathrm{Cl}_{2}$ and was precipitated in cold ether for three times to afford the white solid with $95 \%$ yield. ${ }^{1} \mathrm{H}$ NMR $\left(\mathrm{CDCl}_{3}, 400 \mathrm{MHz}, \mathrm{ppm}\right): \delta$ 2.59-2.63 (m, 4H), $3.38(\mathrm{~s}, 3 \mathrm{H}), 4.23(\mathrm{t}, 2 \mathrm{H}) .{ }^{13} \mathrm{C} \mathrm{NMR}\left(\mathrm{CDCl}_{3}, 400 \mathrm{MHz}, \mathrm{ppm}\right): \delta$ 29.7, 29.9, $58.7,63.6,69.1,70.6,72.1,170.6,175.8$. 
Synthesis of the tadpole-shaped polymer, PEG-POSS-(vinyl) $)_{7}$ (vinyl) $)_{7}-\mathrm{POSS}-\mathrm{OH}(0.3 \mathrm{~g}$, $0.46 \mathrm{mmol})$, PEG-COOH (0.23 g, $0.5 \mathrm{mmol})$, EDCI $(0.11 \mathrm{~g}, 0.55 \mathrm{mmol})$ and DMAP $(12 \mathrm{mg}$, $0.1 \mathrm{mmol}$ ) were added to a $50 \mathrm{~mL}$ round-bottomed flask equipped with a magnetic stirring bar, followed by the addition of $30 \mathrm{~mL}$ of freshly dried $\mathrm{CH}_{2} \mathrm{Cl}_{2}$ to fully dissolve all the solids. The solution was cooled to $0{ }^{\circ} \mathrm{C}$ for $15 \mathrm{~min}$ and allowed to the room temperature, and then further stirred for another $24 \mathrm{~h}$ to complete the reaction. Then, the solution was washed with $2 \mathrm{M} \mathrm{HCl}$ aqueous solution, saturated $\mathrm{NaCl}$ aqueous solution and $\mathrm{DI}$ water for three times and dried over anhydrous $\mathrm{Na}_{2} \mathrm{SO}_{4}$. Then the final product was precipitated into $\mathrm{n}$-hexane for several times to remove the excess (vinyl) $)_{7}$ POSS-OH to afford the white powder with $78.7 \%$ yield. ${ }^{1} \mathrm{H}$ NMR $\left(\mathrm{CDCl}_{3}, 400 \mathrm{MHz}, \mathrm{ppm}\right): \delta 1.19(\mathrm{t}, 2 \mathrm{H}), 2.62(\mathrm{~m}, 4 \mathrm{H}), 3.38(\mathrm{~s}, 3 \mathrm{H}), 3.83(\mathrm{t}, 2 \mathrm{H}), 4.26(\mathrm{t}, 2 \mathrm{H})$, 5.85-6.16 (m, 21H). $\left.{ }^{13} \mathrm{C} \mathrm{NMR} \mathrm{(} \mathrm{CDCl}_{3}, 400 \mathrm{MHz}, \mathrm{ppm}\right): \delta 12.4,28.2,28.6,58.3,60.3,63.1,68.2$, $71.2,127.9,136.4,173.7$.

Synthesis of the azo-monomer, [4-(3-Bromopropoxy)phenyl] phenyldiazene (Azo-Br). 4-phenylazophenol (2 g, $0.01 \mathrm{mmol})$ and 1,3-dibromopropane (4.04 g, $0.02 \mathrm{mmol})$ were dissolved in $50 \mathrm{~mL}$ of THF, and sodium hydroxide $(1 \mathrm{~g}, .25 \mathrm{mmol})$ was slowly added into the solution under argon atmosphere. After refluxing at $80{ }^{\circ} \mathrm{C}$ for $24 \mathrm{~h}$, the reaction mixture was cooled to the room temperature, filtered and rinsed with THF. The filtrate was evaporated under vacuum, and then the final product was further separated chromatographically on silica gel with petroleum ether/ethyl acetate $(\mathrm{v} / \mathrm{v}=20 / 1, \mathrm{Rf}=0.2)$ to afford the orange solid with $31.6 \%$ yield. ${ }^{1} \mathrm{H}$ NMR $\left(\mathrm{CDCl}_{3}, 400 \mathrm{MHz}, \mathrm{ppm}\right): \delta 2.24\left(\mathrm{~m}, 2 \mathrm{H},-\mathrm{OCH}_{2}-\mathrm{CH}_{2}-\mathrm{CH}_{2}-\right), 3.53\left(\mathrm{t}, 2 \mathrm{H},-\mathrm{CH}_{2} \mathrm{Br}\right)$, 4.05 (t, 2H, - $\left.\mathrm{OCH}_{2}-\right), 6.93(\mathrm{~m}, 2 \mathrm{H}, \mathrm{Ar}-\mathrm{H}), 7.40$ (m, 2H, Ar- $\left.\mathrm{H}\right), 7.46$ (m, 3H, Ar- $\left.\mathrm{H}\right), 7.90$ (m, $4 \mathrm{H}, \mathrm{Ar}-\mathrm{H}) .{ }^{13} \mathrm{C} \mathrm{NMR}\left(\mathrm{CDCl}_{3}, 400 \mathrm{MHz}, \mathrm{ppm}\right): \delta 29.7,32.0,65.4,114.5,122.5,124.6,128.9$, 130.3 .

\section{Synthesis of the azo-monomer, [4-(3-Bromopropoxy)phenyl] phenyldiazene (Azo-SH).}

Azo-Br $(1 \mathrm{~g}, 3.12 \mathrm{mmol})$ and thiocarbamide $(1.18 \mathrm{~g}, 15.53 \mathrm{mmol})$ were dissolved in $20 \mathrm{~mL}$ of ethanol under argon atmosphere. After refluxing at $100^{\circ} \mathrm{C}$ for $2 \mathrm{~h}$, the sodium hydroxide solution $(2.5 \mathrm{M}, 20 \mathrm{~mL})$ was added into the red solution and the reaction mixture was further refluxed for $5 \mathrm{~h}$. After that, the solution was cooled to room temperature and $2 \mathrm{M}$ hydrochloric acid was added to adjust the mixture of $\mathrm{pH}=5$. Then the yellow solid was separated, filtered and rinsed with DI water. The resulting filter was extracted with chloroform for three times. The chloroform 
layer was collected and dried over anhydrous $\mathrm{Na}_{2} \mathrm{SO}_{4}$. Finally, the crude product was further separated chromatographically on silica gel with petroleum ether/ethyl acetate $(\mathrm{v} / \mathrm{v}=20 / 1, \mathrm{Rf}=$ $0.3)$ to afford the red solid with $77.6 \%$ yield. ${ }^{1} \mathrm{H}$ NMR $\left(\mathrm{CDCl}_{3}, 400 \mathrm{MHz}, \mathrm{ppm}\right): \delta 1.42(\mathrm{t}, 1 \mathrm{H}$, $-\mathrm{SH}), 2.15\left(\mathrm{~m}, 2 \mathrm{H},-\mathrm{CH}_{2} \mathrm{SH}\right), 2.70\left(\mathrm{~m}, 2 \mathrm{H},-\mathrm{OCH}_{2}-\mathrm{CH}_{2}-\mathrm{CH}_{2}-\right), 4.07\left(\mathrm{t}, 2 \mathrm{H},-\mathrm{OCH}_{2}-\right), 6.97(\mathrm{~m}$, 2H, Ar-H), 7.45 (m, 3H, Ar-H), 7.89 (m, 4H, Ar-H). ${ }^{13} \mathrm{C}$ NMR ( $\left.\mathrm{CDCl}_{3}, 400 \mathrm{MHz}, \mathrm{ppm}\right): \delta$ 21.2, $33.2,66.1,114.7,122.6,124.9,129.1,130.4$.

\section{Synthesis of the amphiphilic hemi-telechelic polymer, PEG-POSS-(Azo $)_{7}$.} PEG-POSS-(vinyl) 7 (0.2 g, $0.2 \mathrm{mmol})$, Azo-SH (0.41 g, $1.5 \mathrm{mmol})$ and DMPA (25 mg, $0.1 \mathrm{mmol})$ were dissolved in $10 \mathrm{~mL}$ of THF. After irradiation under a $365 \mathrm{~nm}$ UV lamp at room temperature for $4 \mathrm{~h}$ to make sure no vinyl groups existed. The product was precipitated into ether for several times to afford the red solid with $65.5 \%$ yield. ${ }^{1} \mathrm{H}$ NMR $\left(\mathrm{CDCl}_{3}, 400 \mathrm{MHz}, \mathrm{ppm}\right): \delta 1.21(\mathrm{t}, 14 \mathrm{H})$, $1.25(\mathrm{t}, 2 \mathrm{H}), 2.11(\mathrm{~m}, 14 \mathrm{H}), 2.39(\mathrm{t}, 14 \mathrm{H}), 2.99(\mathrm{t}, 14 \mathrm{H}), 2.65(\mathrm{~m}, 4 \mathrm{H}), 3.38(\mathrm{~s}, 3 \mathrm{H}), 3.83(\mathrm{t}$, $2 \mathrm{H}), 4.16(\mathrm{t}, 14 \mathrm{H}), 4.26(\mathrm{t}, 2 \mathrm{H}), 7.40(\mathrm{~m}, 14 \mathrm{H}, \mathrm{Ar}-\mathrm{H}), 7.46(\mathrm{~m}, 21 \mathrm{H}, \operatorname{Ar}-\mathrm{H}), 7.90(\mathrm{~m}, 28 \mathrm{H}$, $\mathrm{Ar}-H) .{ }^{13} \mathrm{C} \mathrm{NMR}\left(\mathrm{CDCl}_{3}, 400 \mathrm{MHz}, \mathrm{ppm}\right): \delta 11.7,12.4,20.7,26.2,27.9,28.6,32.4,58.2,60.2$, $63.0,65.8,68.2,69.7,71.2,114.0,121.8,124.1,128.2,129.7,171.3$.

Formation and self-assembly of the amphiphilic tadpole-shaped polymer. A typical self-assembly aggregate solution was prepared as following: PEG-POSS-(Azo $)_{7}(5 \mathrm{mg})$ was first dissolved in THF (1 mL), which is a good solvent for POSS, Azo and PEG components. Then deionized water $(4 \mathrm{~mL})$ was added dropwise into the solution at the rate of $0.05 \mathrm{~mL} / \mathrm{min}$ via a syringe pump. The colloidal dispersion was further stirred for another $2 \mathrm{~h}$ and the temperature was fixed at $30{ }^{\circ} \mathrm{C}$ during the self-assembling process. The organic solvent (THF) was removed by dialysis (MW cutoff, $1 \mathrm{kDa}$ ) against deionized water for 3 days.

Irradiation experiments. The water dispersions of self-assemblies were irradiated with a compact mercury low pressure fluorescent lamp Philips PL-S 9W emitting irradiation at $365 \mathrm{~nm}$. The samples were placed at a distance of $10 \mathrm{~cm}$ from the light source in quartz cuvettes at room temperature. After irradiation, the water suspensions were kept in the dark for $24 \mathrm{~h}$.

Loading of three fluorescent dyes into the vesicle. In order to encapsulate the various dyes, vesicular formation was carried out following the same procedure described for the polymersomes and using a solution of TPE, FITC, RhB in water respectively. The 
tadpole-shaped polymer was first dissolved in THF and a solution of fluorescent dyes was gradually added to induce the self-assembly into vesicles. The charge ratio was 1:2 (mol polymer/mol dye). Self-assembly was followed by monitoring the turbidity and once the encapsulated micelles were prepared, the mixture was then dialyzed against water to remove THF and non-encapsulated fluorescent dyes for hydrophilic dyes or centrifugation treatment for hydrophobic dyes.

DPD simulation method. Dissipative particle dynamics (DPD) simulation was performed to understand the assembly of PEG-POSS-(Azo $)_{7}$ in water. In the DPD simulation we constructed a specific coarse-grained (CG) model of PEG-POSS-(Azo) $)_{7}$ wherein eight branches were attached to one big CG POSS bead. As shown in Scheme S1, there were three types of beads, P, G and A for POSS, PEG and Azo. According to the molecular size in all-atom simulation, the model was simplified to a big POSS CG bead with seven Azo CG bead and two PEG CG beads in line. The interaction parameter $\mathrm{a}_{\mathrm{ij}}$ between different beads was presented in the following Table S1, which followed Wang's work. ${ }^{1}$

Within the CG model, neighboring CG beads are bonded to each other by a harmonic spring potential, $\mathrm{U}_{\mathrm{b}}=0.5 \mathrm{k}_{\mathrm{b}}\left(\mathrm{r}-\mathrm{r}_{0}\right)^{2}$, where $\mathrm{k}_{\mathrm{b}}$ is the spring constant and $\mathrm{r}_{0}$ is the equilibrium bond length. In this study, $\mathrm{k}_{\mathrm{b}}=25$ and $\mathrm{r}_{0}=0.7$. The concentration of PEG-POSS-(Azo $)_{7}$ in the solution $\varphi$ is 0.05 , which is calculated by the following formula.

$$
\varphi=\frac{N_{P} V_{P}+N_{G} V_{G}+N_{A} V_{A}}{N_{P} V_{P}+N_{G} V_{G}+N_{A} V_{A}+N_{W} V_{W}}
$$

Where $N_{P}, N_{G}, N_{A}$ and $N_{W}$ are the number of POSS, PEG, Azo and water beads while $V_{P}, V_{G}$, $\mathrm{V}_{\mathrm{A}}$ and $\mathrm{V}_{\mathrm{W}}$ are the volume of one bead of POSS, PEG, Azo and solvent, respectively.

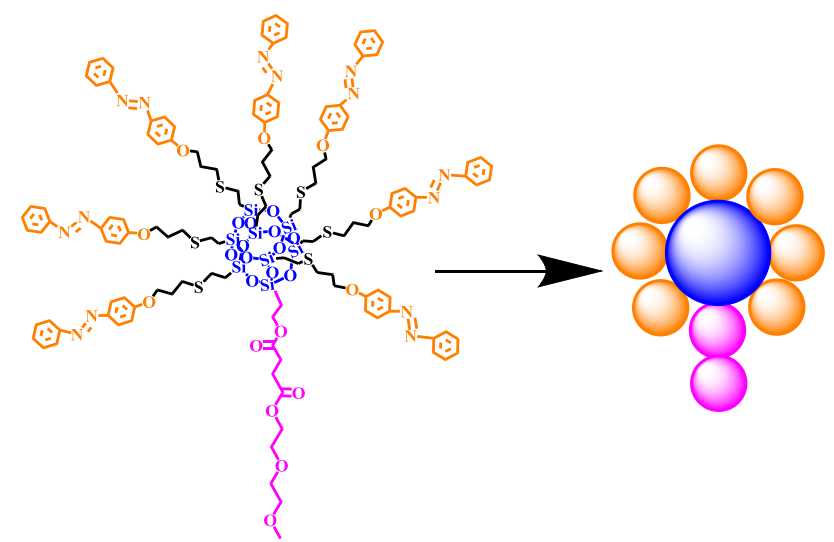

Scheme S1. Scheme of PEG-POSS-(Azo) $)_{7}$ CG model, the blue, orange, and purple bead represent POSS bead, Azo bead and PEG bead, respectively. 
Table S1. The repulsion parameters for different beads in CG model.

\begin{tabular}{ccccc}
\hline $\mathbf{a}_{\mathrm{ij}}$ & $\mathbf{P}$ & $\mathbf{G}$ & $\mathbf{A}$ & $\mathbf{W}$ \\
\hline $\mathrm{P}$ & 25 & 50 & 25 & 50 \\
$\mathrm{G}$ & & 25 & 25 & 25 \\
$\mathrm{~A}$ & & 25 & 26 \\
$\mathrm{~W}$ & & & 25 \\
\hline
\end{tabular}

Here $\mathrm{P}$ for POSS, $\mathrm{G}$ for PEG, A for Azo, $\mathrm{W}$ for water.

The size of simulation box was $30 \times 30 \times 30$. The simulation was performed in NVT ensemble with periodical boundary conditions applied in all three dimensions and at a fixed system number density of 3.0. All the CG beads had the same mass as $m=1$. The interaction cutoff radius was set to 1 as the unit of length. The size of POSS was 3 times of Azo, PEG or water beads. The temperature was 1.0. In the CG simulation the modified velocity-verlet algorithm was used to integrate the equations of motion with a time step of 0.03 . We started simulations from isotropic configurations, which were constructed by equilibrating the systems under a thermal conditions, i.e., by setting $\mathrm{a}_{\mathrm{ij}}=25$ and $\mathrm{T}=1.0$ for all DPD beads and ran $1 \times 10^{6}$ steps for equilibrium. Then we performed $3 \times 10^{6}$ steps to observe the morphology of aggregates at equilibrium.

1. Ma, S. Y.; Hu, Y.; Wang, R. Macromolecules 2015, 48, 3112-3120.



Figure S1. ${ }^{1} \mathrm{H}$ and ${ }^{13} \mathrm{C}$ NMR spectra of PEG-COOH at $\mathrm{CDCl}_{3}$. 


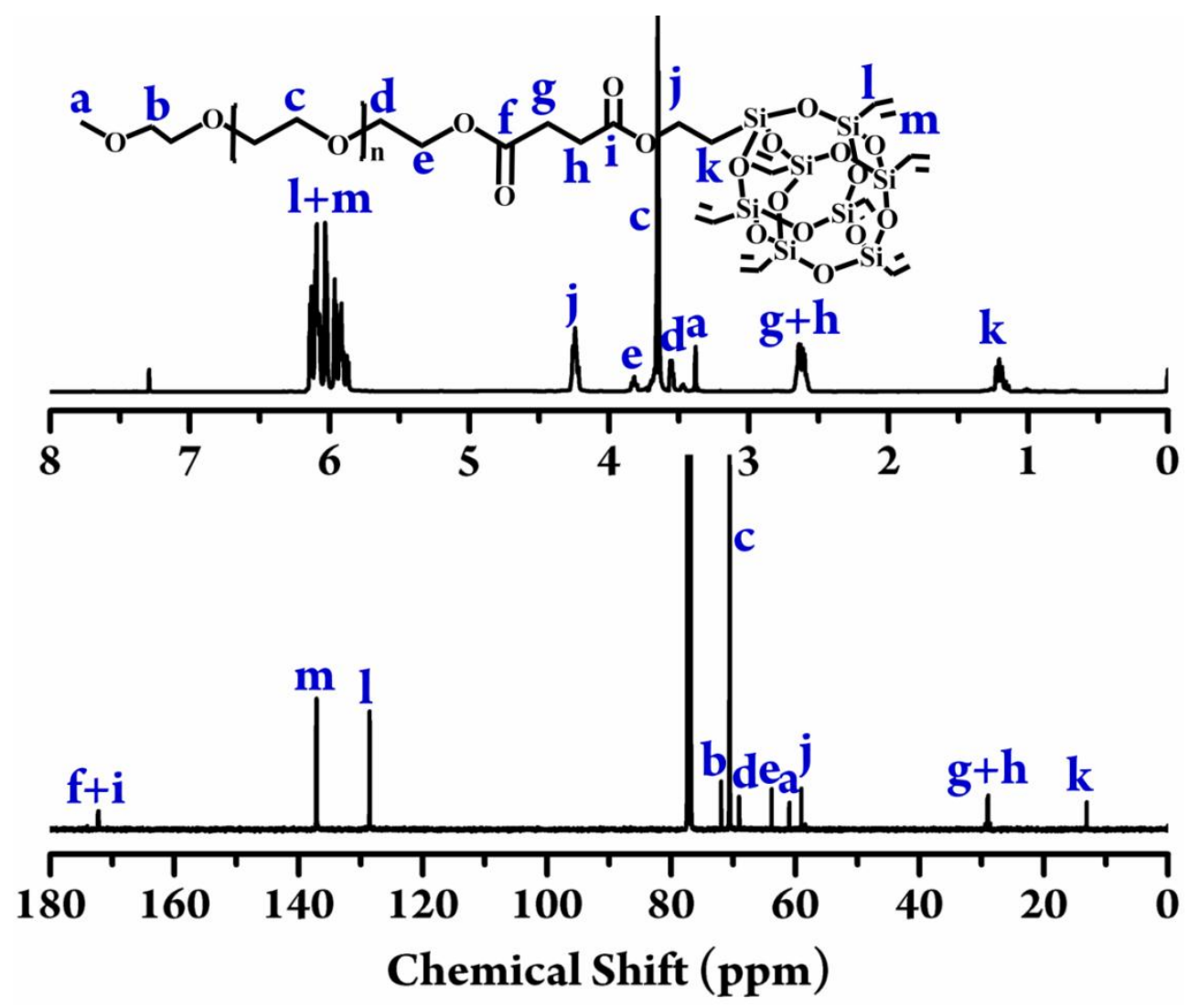

Figure S2. ${ }^{1} \mathrm{H}$ and ${ }^{13} \mathrm{C}$ NMR spectra of PEG-POSS-(vinyl) ${ }_{7}$ at $\mathrm{CDCl}_{3}$.

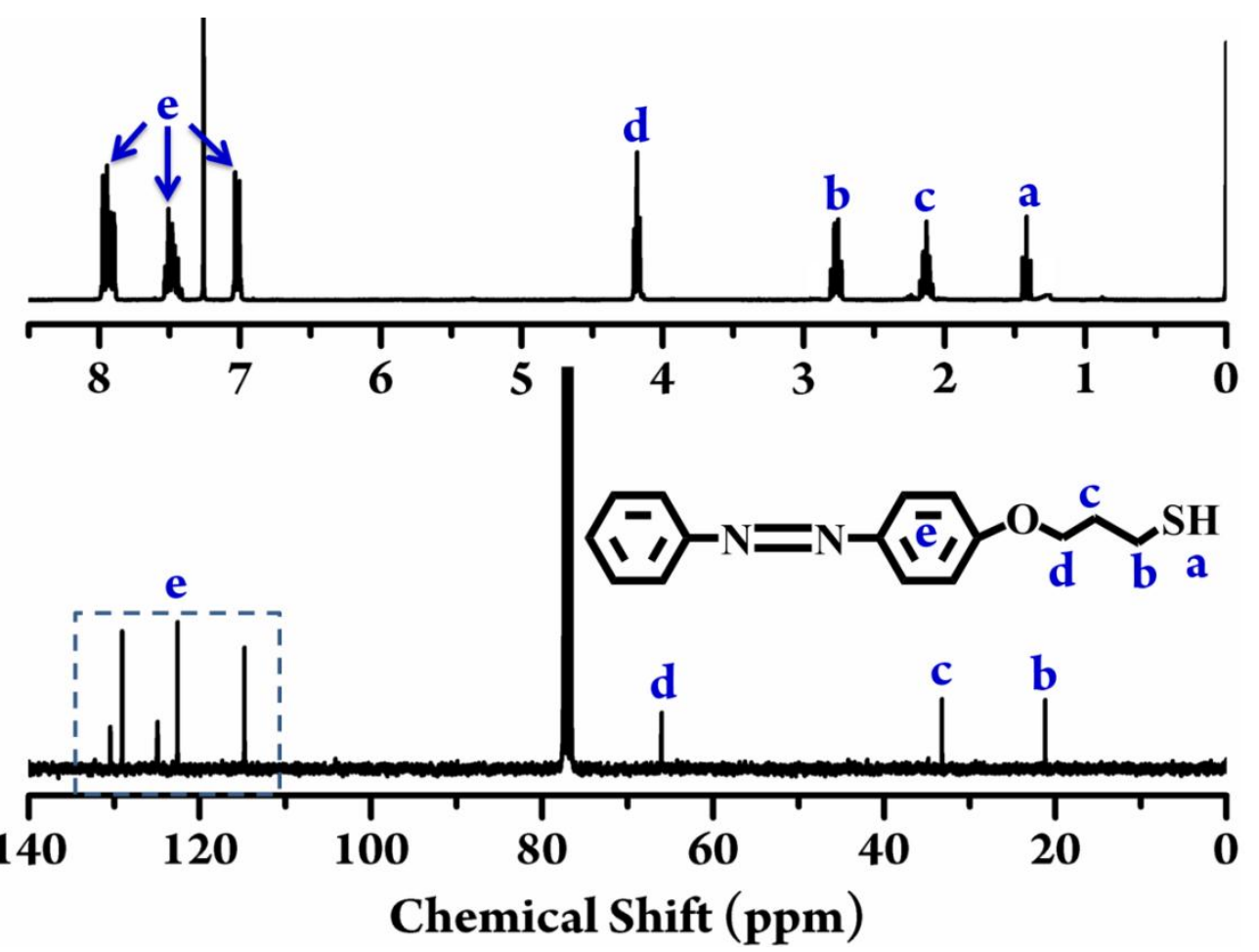

Figure S3. ${ }^{1} \mathrm{H}$ and ${ }^{13} \mathrm{C}$ NMR spectra of Azo-SH at $\mathrm{CDCl}_{3}$. 
Table S2. Molecular weight of tadpole-shaped polymers and the corresponding size of self-assembled aggregations determined via TEM, SEM and DLS.

\begin{tabular}{|c|c|c|c|c|c|c|}
\hline \multirow{2}{*}{ Sample } & \multicolumn{3}{|c|}{ Molecular weight } & \multicolumn{3}{|c|}{ Size of assembles } \\
\hline & $M_{n}^{\text {Calc }}$ & $M_{n}^{\text {GPC }}$ & $M_{w} / M_{n}{ }^{G P C}$ & $\mathbf{d}^{\mathrm{TEM}}(\mathbf{n m})$ & $\mathbf{d}^{\operatorname{SEM}}(\mathbf{n m})$ & $\mathbf{d}^{\mathrm{DLS}}(\mathbf{n m})$ \\
\hline \multirow[t]{2}{*}{ PEG-POSS-(vinyl) ${ }_{7}$} & 1082 & 980 & 1.04 & 520 & 560 & 610 \\
\hline & & & & $580^{a}$ & $450^{\mathrm{a}}$ & $650^{\mathrm{a}}$ \\
\hline \multirow[t]{2}{*}{ PEG-POSS-(Azo $)_{7}$} & 2886 & 3000 & 1.05 & & & \\
\hline & & & & $480^{\mathrm{b}}$ & $420^{\mathrm{b}}$ & $680^{\mathrm{b}}$ \\
\hline
\end{tabular}

${ }^{\mathrm{a}}$ PEG-POSS-(Azo $)_{7}$ vesicles before UV irradiation. ${ }^{\mathrm{b}}$ PEG-POSS-(Azo $)_{7}$ vesicles after UV irradiation.

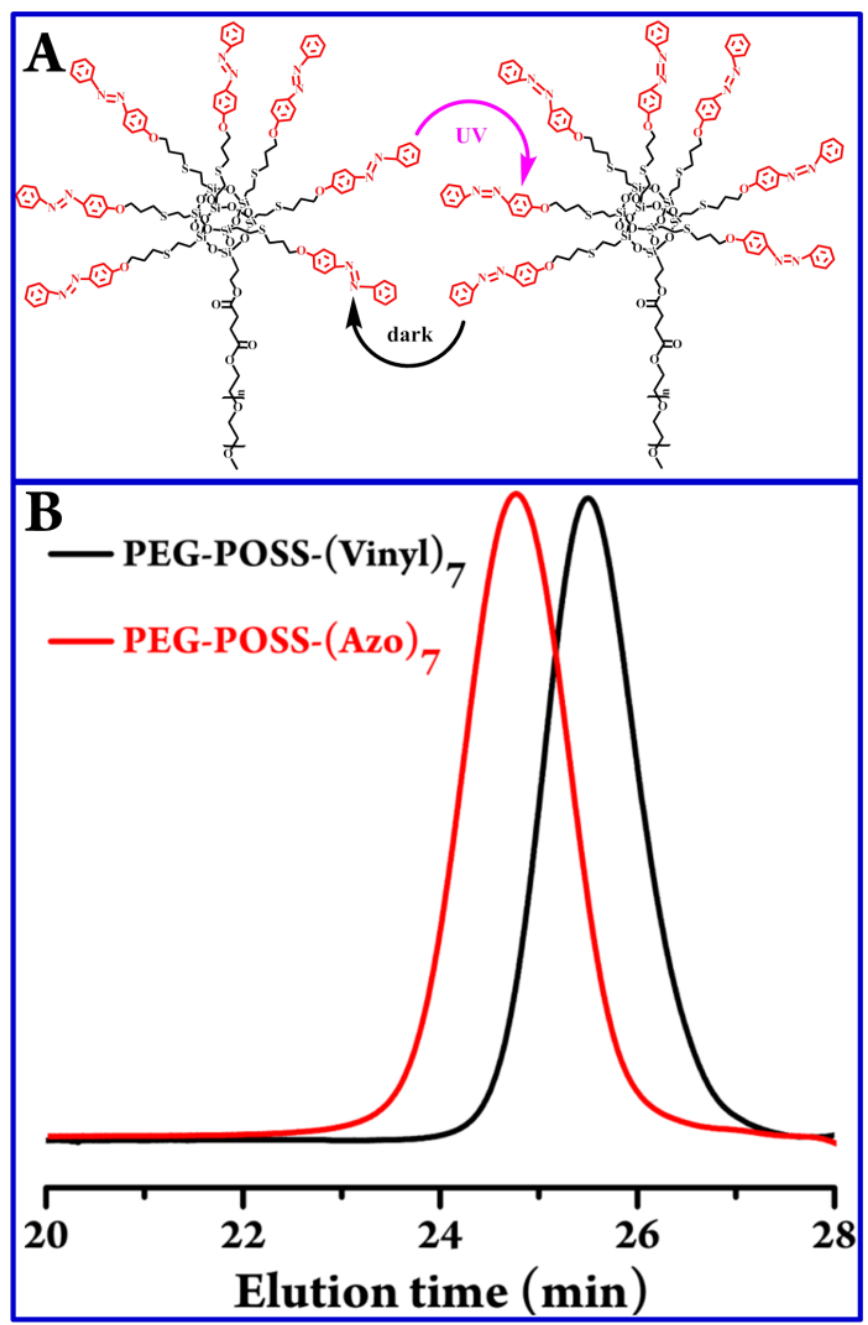

Figure S4. (A) Illustration of reversible trans-cis isomerization under UV and dark conditions.

(B) GPC curves of PEG-POSS-(vinyl $)_{7}$ and PEG-POSS-(Azo $)_{7}$ polymers. 


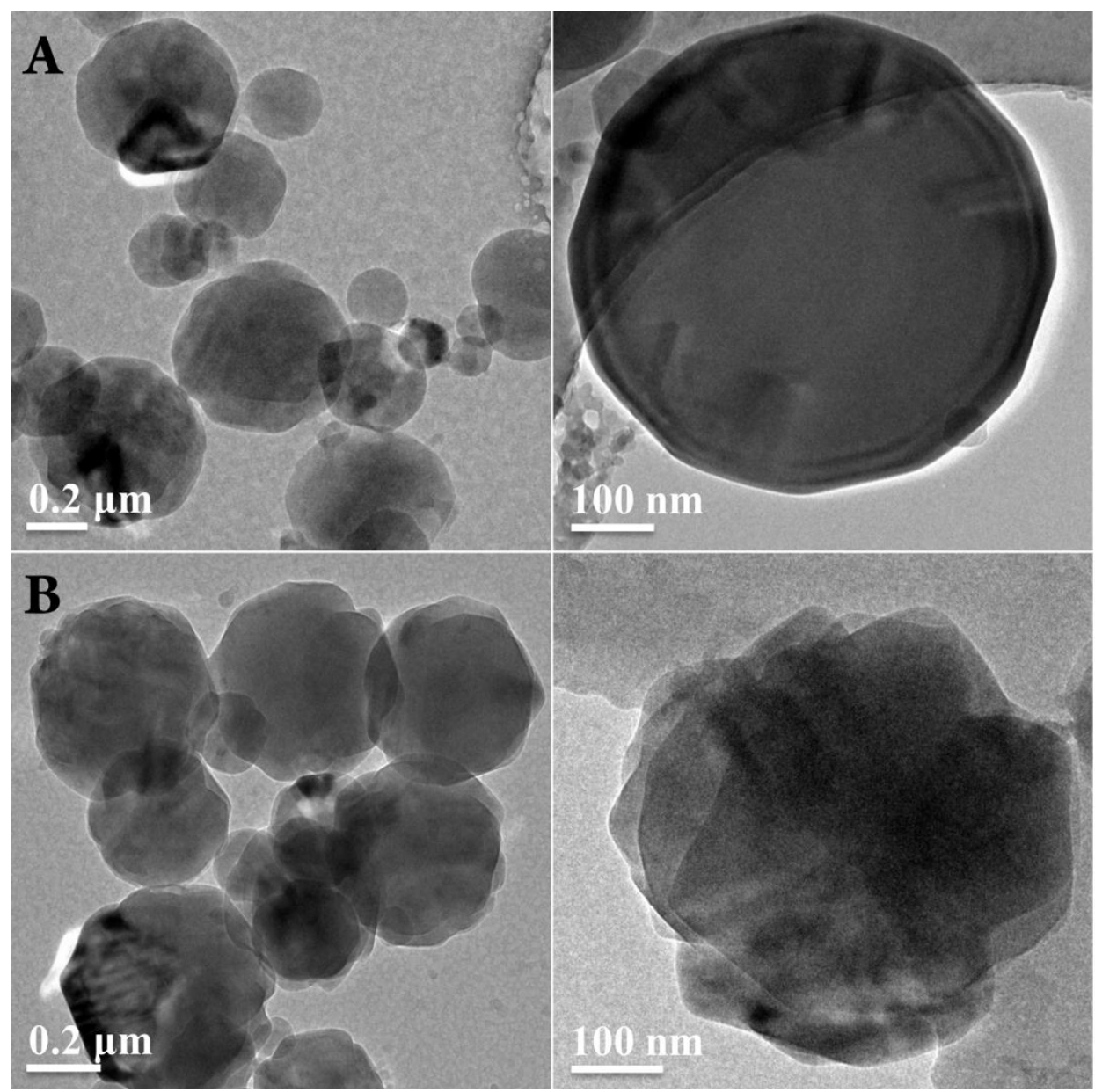

Figure S5. Cryo-TEM images of the morphologies self-assembled from PEG-POSS-(Azo) 7 (A) before and (B) after UV irradiation.

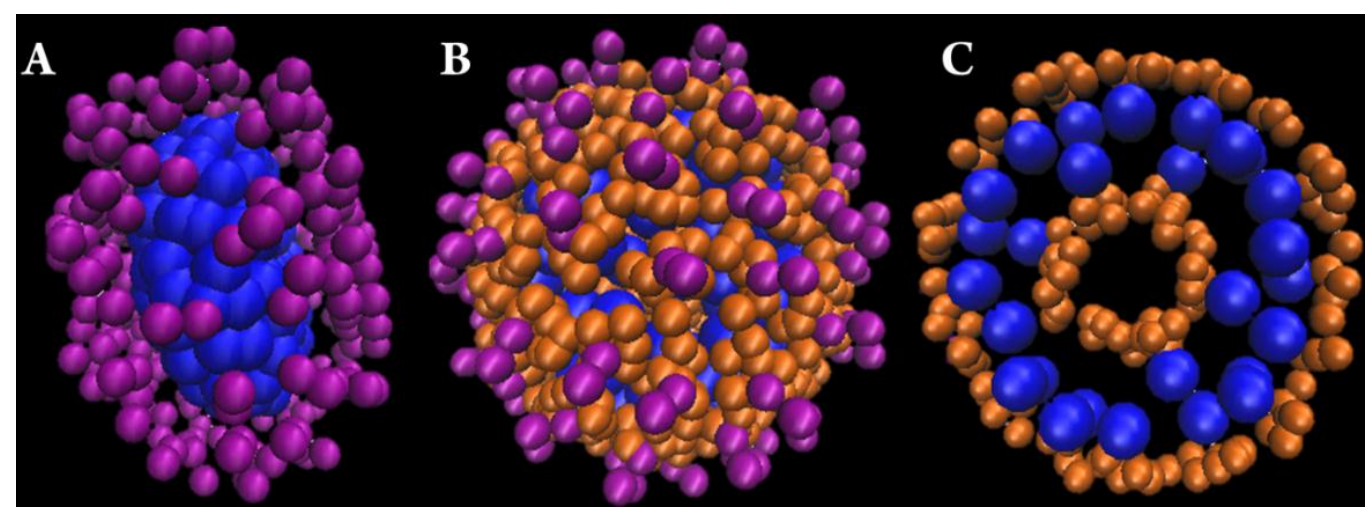

Figure S6. The morphologies of the aggregates formed after $3 \times 10^{5}$ time steps DPD simulations from amphiphilic tadpole-shaped polymers based on (A) PEG-POSS-(vinyl) PEG-POSS-(Azo $)_{7}$ and (C) the profile of (B) along the equator. Water beads are omitted for clarity. The blue, purple and orange beads represent coarse grained POSS, PEG and Azo, respectively. The bonds between polymer beads are also omitted for clarity. 


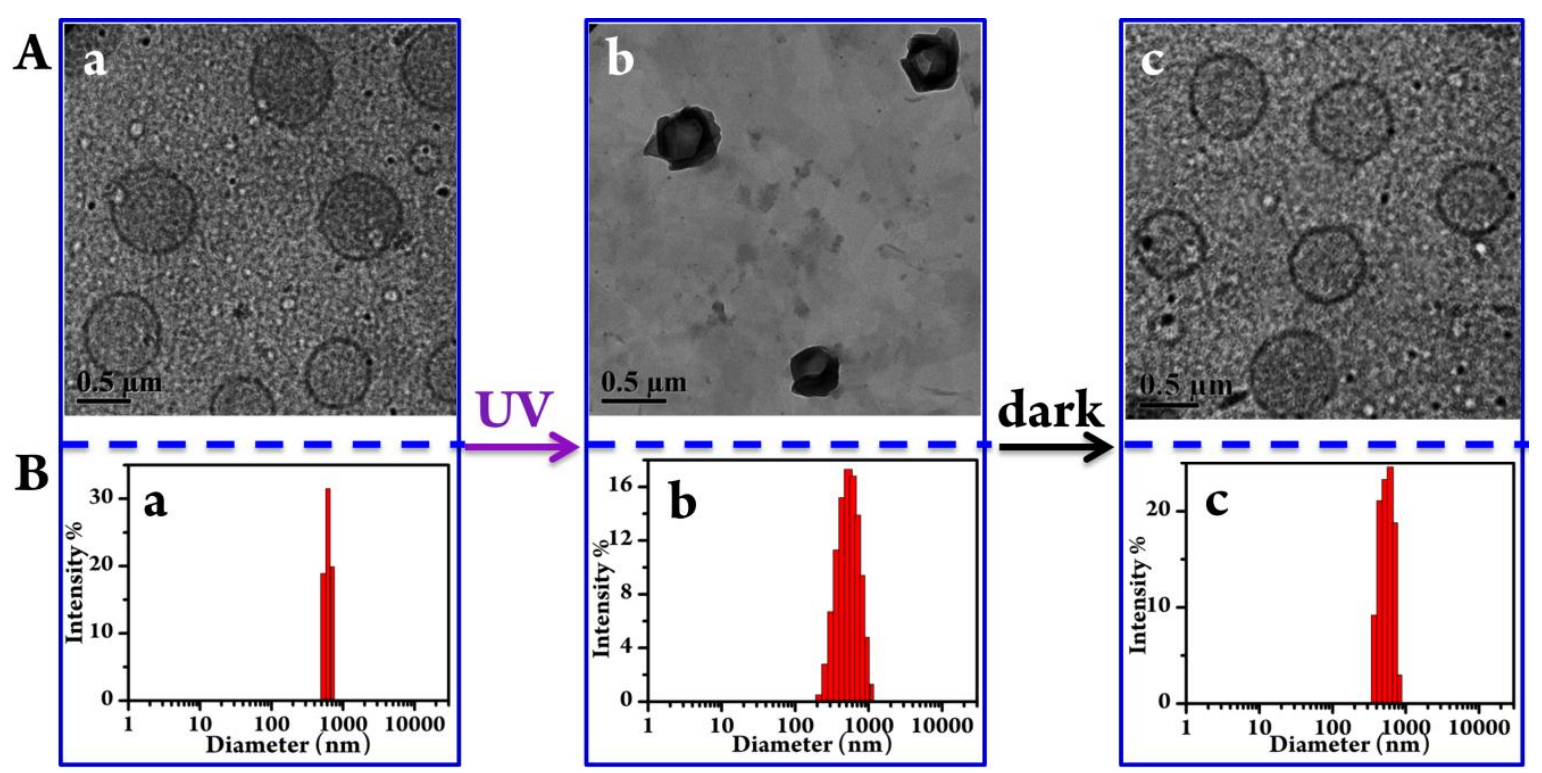

Figure S7. (A) TEM images and (B) DLS profiles of PEG-POSS-(Azo) $)_{7}$ vesicles before (a), after (b) UV irradiation for $2 \mathrm{~min}(365 \mathrm{~nm}, 9 \mathrm{~W})$, and after $24 \mathrm{~h}$ in the dark (c).

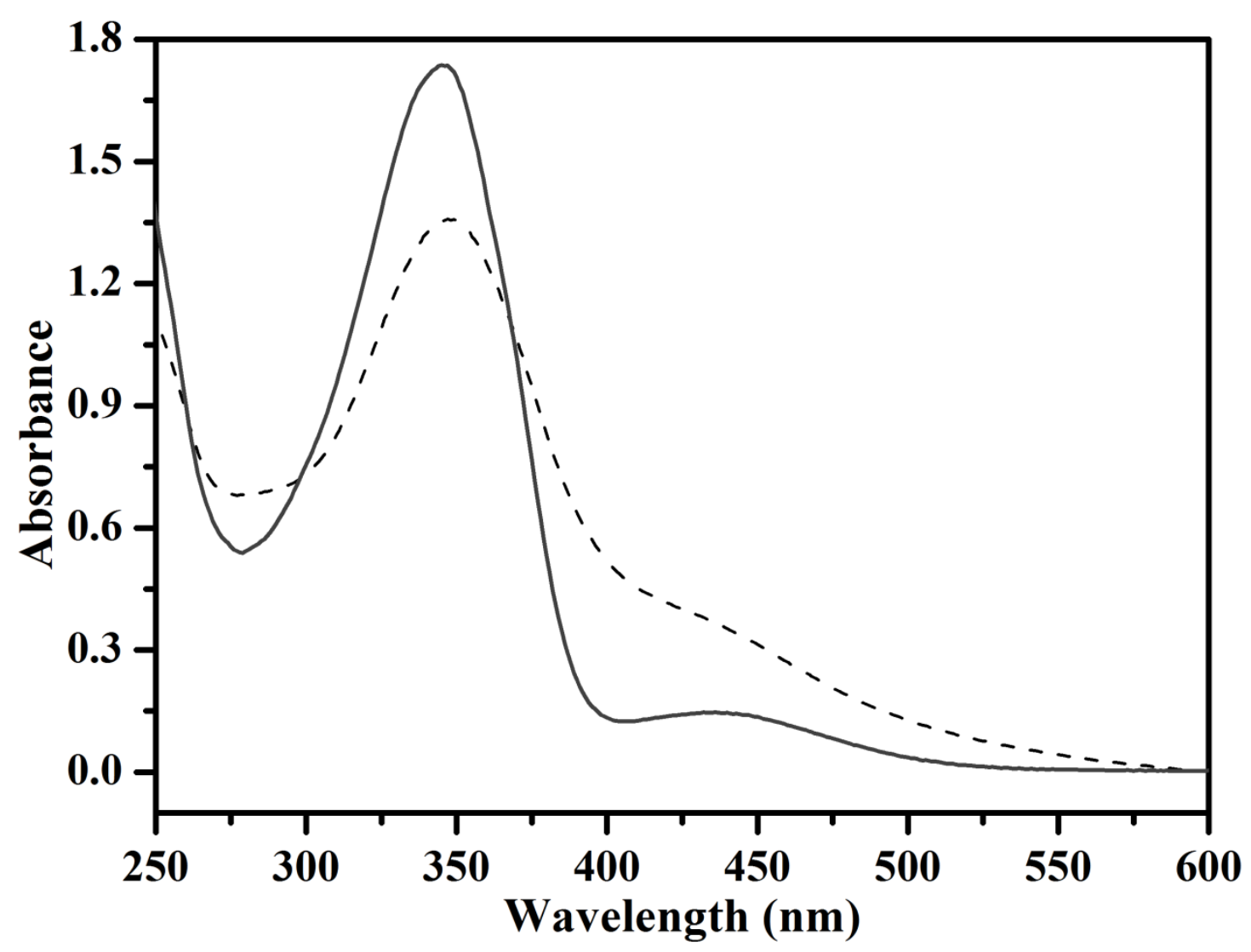

Figure S8. UV-vis spectra of PEG-POSS-(Azo $)_{7}$ in a $5 \times 10^{-6} \mathrm{~mol} \mathrm{~L}^{-1}$ solution in $\mathrm{CHCl}_{3}$ (straight line) and a water suspension of PEG-POSS-(Azo $)_{7}$ vesicles (dashed line). 
Table S3. Sizes of the various dye-encapsulated assembles determined by TEM and DLS.

\begin{tabular}{ccc}
\hline \multirow{2}{*}{ Sample } & \multicolumn{2}{c}{ Size of assembles } \\
\cline { 2 - 3 } & TEM $(\mathbf{n m})$ & DLS $(\mathbf{n m})$ \\
\hline TPE-encapsulated & 600 & 650 \\
FITC-encapsulated & 130 & 400 \\
RhB-encapsulated & 110 & 680 \\
\hline
\end{tabular}

